\title{
Thermal discrimination thresholds in normal subjects and in patients with diabetic neuropathy
}

\author{
FW BERTELSMANN, ${ }^{*} \mathrm{JJ}$ HEIMANS, ${ }^{*}$ EJM WEBER,${ }^{*}$ EA van der VEEN, $\dagger$ \\ JA SCHOUTEN† \\ From the Departments of Neurology* and Internal Medicine, $\dagger$ Free University Hospital, Amsterdam, the \\ Netherlands
}

SUMmary Using two identical thermostimulators which operated on the Peltier principle, thermal cutaneous sensation of the hand and the foot was investigated in 36 normal subjects and in 20 patients with diabetic neuropathy. Using a two-alternative forced-choice testing procedure, thermal discrimination thresholds were determined twice. The values found in normal subjects are comparable with data from the literature. It was confirmed that thermal discrimination of the foot decreased with increasing age. In patients with diabetic neuropathy the increased thresholds for the foot could be correlated with length-dependent degeneration of small nerve fibres.

In patients with diabetic neuropathy it may be important to quantitate the results of sensory examination, for example when evaluation of the effect of therapy is required..$^{-3}$ Many attempts have been made to measure various qualities of cutaneous sensation. Equipment has been developed to determine perception thresholds for vibration, tactile stimuli and thermal stimuli. ${ }^{3}$

An increased thermal perception threshold in patients with diabetic neuropathy is a reflection of the loss of small fibre function. ${ }^{4}$ The bedside methods used to examine thermal sensation are inadequate to allow monitoring of this function. ${ }^{3}$ Nowadays convenient thermostimulators, operating on the Peltier principle, make it possible to determine the thermal perception threshold. ${ }^{5}$ The methods of testing cutaneous thermal discrimination, which are described in various reports, differ considerably and are not always free of response bias. $^{5-8}$ We used the Peltier effect to vary the temperature of two identical thermostimulators and employed a two-alternative forced-choice testing procedure. Thermal discrimination thresholds were determined for the dorsum of the hand and the dorsum of the foot in a group of healthy volunteers and in a group of patients suffering from diabetic neuropathy.

\footnotetext{
Address for reprint requests: FW Bertelsmann, Department of Neurology, Free University Hospital, De Boelelaan 1117, PO Box 7057, 1007 MB Amsterdam, the Netherlands.
}

Received 20 August 1984 and in revised form 9 November 1984. Accepted 17 November 1984

\section{Materials and methods}

\section{Subjects}

Thirty-six nondiabetic subjects, 25 women and 11 men, varying in age from 24 to 91 years, and 20 diabetic patients, 11 women and nine men, varying in age from 22 to 69 years, were investigated. All nondiabetic subjects were healthy and did not receive any medication interfering with sensory function. Neurological examination was normal and peripheral arterial pulsations were intact. All diabetic patients examined were insulin-dependent (Type 1) and had symptoms and/or signs of neuropathy. Thirteen patients had sensory complaints (numbness, spontaneous pain or paraesthesia in the lower limbs) together with absent ankle jerks and decreased motor conduction velocities of peroneal and median nerves. Four patients had sensory complaints together with either decreased nerve conduction velocities or absent ankle jerks. Three patients had no sensory complaints but ankle jerks were absent and nerve conduction velocities were decreased.

\section{Equipment and procedure}

The testing equipment is composed of a control unit and two thermostimulators. Each thermostimulator employs an element, operating on the Peltier principle, and measuring $3 \mathrm{~cm} \times 4 \mathrm{~cm}$. By varying the direction of the current through the Peltier element the thermostimulator can be warmed or cooled. A spring mechanism ensures that the stimulator is applied with a constant $(200 \mathrm{~g})$ pressure to the area of skin to be tested. One thermostimulator (TS1) is set and maintained at a temperature which equals the skin-temperature of the area tested. The temperature of the second stimulator (TS2) is varied and is randomly adjusted so that it is higher or lower than the temperature of TS1. The temperature of TS1, TS2 and the difference between them can be displayed on the control unit. The 


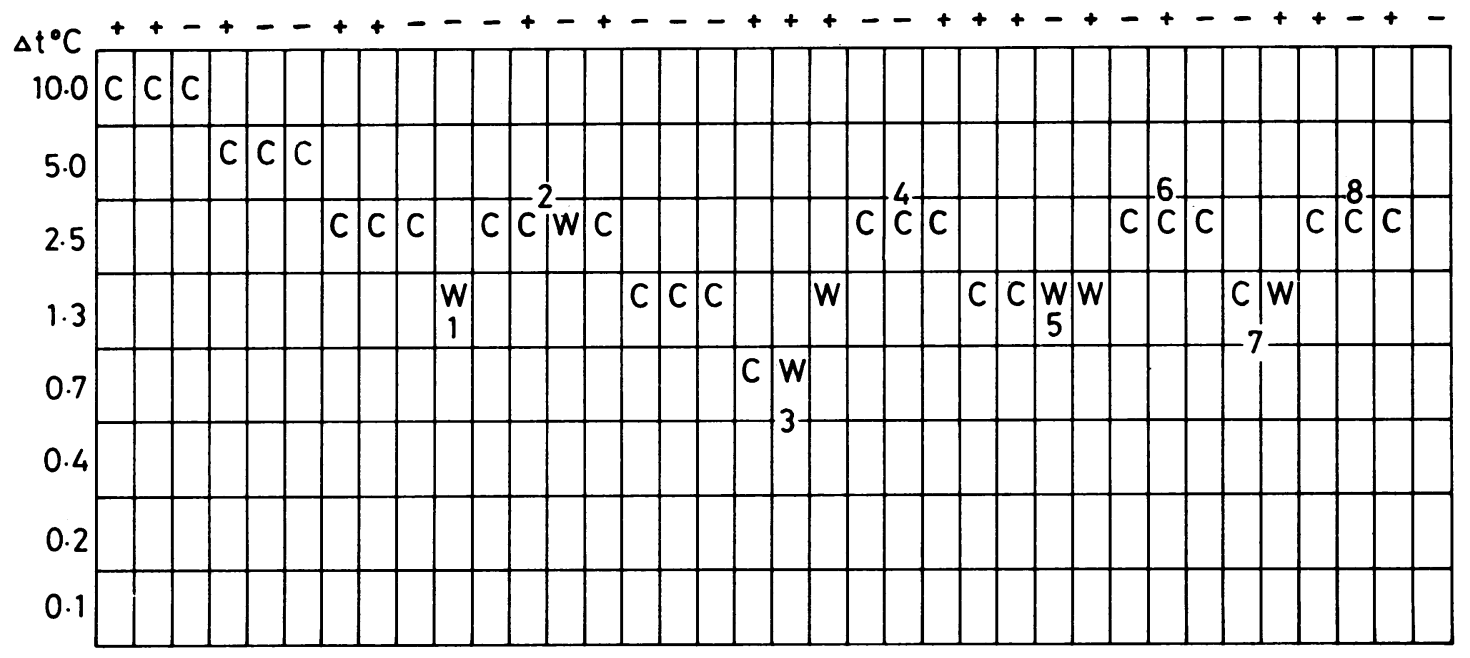

Trial

Fig 1 Test result (left foot) in a patient with diabetic neuropathy. $\Delta t$ is the temperature difference between the two stimulators. The reversal points are numbered from 1 to 8. Thermal discrimination threshold is the mean value of the last six reversals, in this case $1.8^{\circ} \mathrm{C} . C=$ correct response. $W=$ wrong response. $+1-=$ stimulator two is warmer/cooler than stimulator one. See text for further explanation.

maximum difference in temperature between the two stimulators can be $10 \cdot 0^{\circ} \mathrm{C}$, whilst the minimum difference is $0.1^{\circ} \mathrm{C}$. A two-alternative forced-choice test method is used. The investigator applies TS1 for $3 \mathrm{~s}$ at the testing site. Subsequently, TS2 is applied and when it is removed after another $3 \mathrm{~s}$, the subject is asked whether TS2 was warmer or cooler than TS1. At the beginning of the test procedure the temperature difference between the two thermostimulators is $10.0^{\circ} \mathrm{C}$. Using a logarithmic scale, other temperature differences used in the test are $5.0^{\circ} \mathrm{C}, 2.5^{\circ} \mathrm{C}$, $1.3^{\circ} \mathrm{C}, 0.7^{\circ} \mathrm{C}, 0.4^{\circ} \mathrm{C}, 0.2^{\circ} \mathrm{C}$, and $0.1^{\circ} \mathrm{C}$ (fig 1). The interval between two pairs of consecutive stimuli is $12 \mathrm{~s}$. After a correct answer from the subject, the temperature differ-

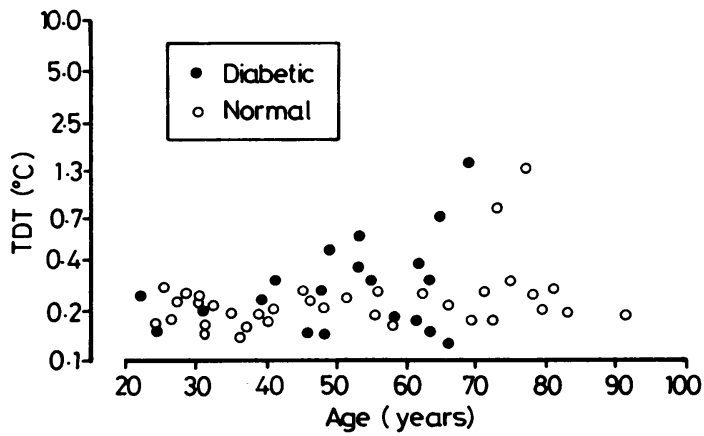

Fig 2 Representation of left hand thermal discrimination thresholds (mean value of two examinations) in 36 normal subjects $(O)$ and 20 patients with diabetic neuropathy $(O)$ as a function of age. ence between the stimulators is reduced. If an error is made the temperature difference is increased (up and down rule).

An answer is judged to be correct after a correct response to three identical temperature differences (CCC), or after a sequence of two correct responses, a wrong response and a correct response (CCWC). Conversely, a wrong response (W), a sequence of a correct response and a wrong response $(\mathrm{CW})$, and a sequence of two correct responses and two wrong responses $(\mathrm{CCWW})$ are judged to be errors (fig 1).

Using these rules and testing at the temperature differences mentioned above, eight changes in direction are registered (reversal points). The discrimination threshold is defined as the mean value of the last six reversals.

The subject is familiarised with the procedure, and allowed to acclimatise for $\mathbf{2 0}$ minutes in the examination room. Usually it takes 15 minutes to determine the thermal discrimination threshold. In all subjects, thermal discrimination thresholds were determined twice, both for the dorsum of the left hand and the dorsum of the left foot. The two examinations were separated by a period of one week.

\section{Results}

In the majority of normal subjects, the thermal discrimination threshold on the dorsum of the hand was in the range $0 \cdot 15^{\circ} \mathrm{C}$ to $0 \cdot 30^{\circ} \mathrm{C}$. Two subjects over 70 years of age gave thermal discrimination threshold values of $0.75^{\circ} \mathrm{C}$ and $1.30^{\circ} \mathrm{C}$ (fig 2). All diabetic patients tested were under 70 years of age. In 14 of them, thermal discrimination threshold on the hand ranged between $0 \cdot 15^{\circ} \mathrm{C}$ and $0 \cdot 30^{\circ} \mathrm{C}$. In six 


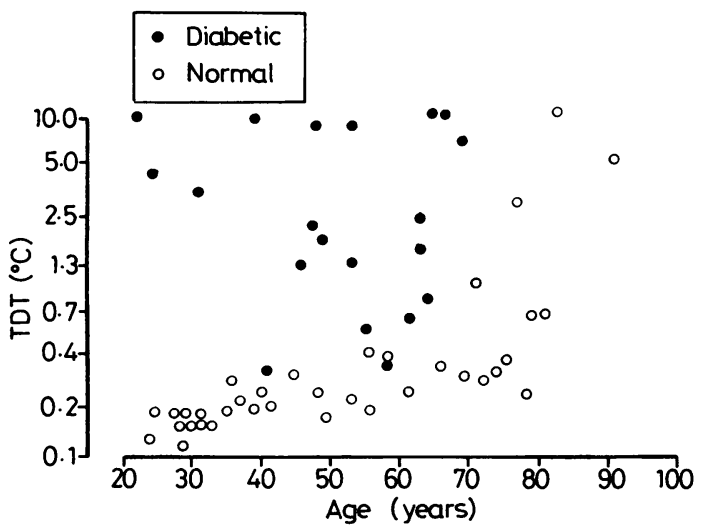

Fig 3 Representation of left foot thermal discrimination thresholds (mean value of two examinations) in 36 normal subjects $(\bigcirc)$ and 20 patients with diabetic neuropathy $(\odot)$ as a function of age.

diabetics the thermal discrimination threshold on the dorsum of the hand exceeded $0 \cdot 30^{\circ} \mathrm{C}$ (fig 2).

In all normal individuals under 70 years of age, the thermal discrimination threshold on the foot was between $0.15^{\circ} \mathrm{C}$ and $0.50^{\circ} \mathrm{C}$. However, in six older subjects, a marked elevation of thermal discrimination threshold was noted (fig 3 ). In all but two patients with diabetic neuropathy, thermal discrimination thresholds on the foot exceeded $0.50^{\circ} \mathrm{C}$ with values ranging from $0 \cdot 60^{\circ} \mathrm{C}$ to over $10 \cdot 0^{\circ} \mathrm{C}$ (fig 3).

All normal and diabetic subjects were tested twice

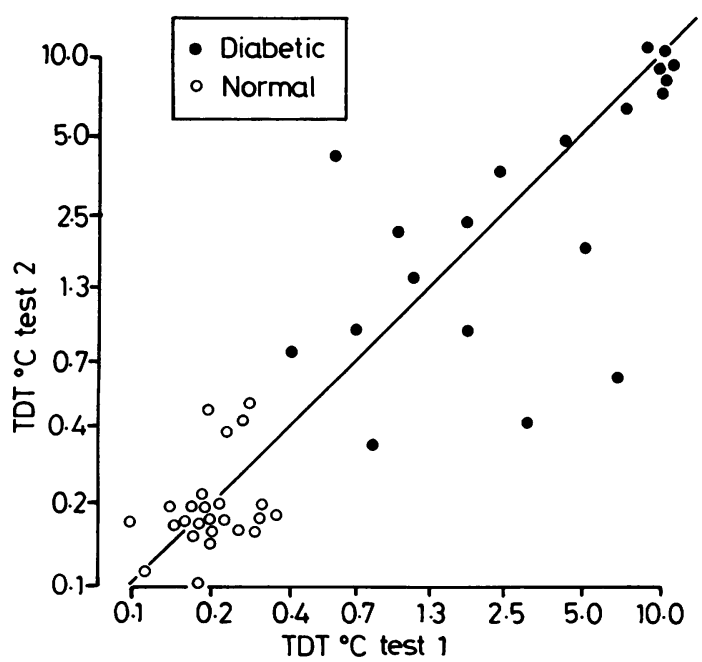

Fig 4 Correlation of left foot thermal discrimination thresholds found in two examinations (interval of 1 week) in 25 normal subjects under 70 years of age $(O)$ and in 20 patients with diabetic neuropathy (O). in order to examine intra-individual variability. The maximum difference between two examinations of the thermal discrimination threshold was $0.50^{\circ} \mathrm{C}$ for both the hand and the foot in normal subjects, and for the hand in diabetic patients. Figure 4 represents the intra-individual variability of the thermal discrimination threshold for the foot in $\mathbf{3 0}$ normal subjects under 70 years of age and in 20 patients with diabetic neuropathy, and allows a comparison of the reproducibility of normal and increased thresholds.

\section{Discussion}

Establishing a diagnosis of diabetic neuropathy is a well known problem in clinical practice. The patient may have symptoms in the absence of clinical and neurophysiological signs. In contrast, the neurological and neurophysiological examination may show abnormalities in asymptomatic diabetics. ${ }^{9}$ The conventional methods for determining motor and sensory nerve conduction velocities only reflect the conduction velocity of large myelinated nerve fibres. ${ }^{10}$ It is generally accepted that thermal sensations are conducted by the small myelinated fibres (delta group A-axons) and the smaller unmyelinated fibres (C-axons) of the peripheral nerve (according to Erlanger and Gasser's nomenclature).$^{34611}$ Thus investigation of thermal cutaneous sensation provides additional information when examining a patient. ${ }^{17}$ Particularly in patients with symptoms but without clinical and neurophysiological abnormalities, quantitation of cutaneous sensation can identify neuropathy. ${ }^{12}$ Moreover, quantitation of cutaneous sensation offers the possibility of evaluating the effects of therapy, for example administration of aldose reductase inhibitors ${ }^{1314}$ or improved metabolic control of diabetes mellitus. ${ }^{121516}$

Several methods for quantitation of thermal sensation have been developed. ${ }^{s-8}$ On theoretical grounds, thermal stimulation without a tactile component would be ideal. This can be achieved by using a radiation stimulus. ${ }^{17}$ The actual temperature change cannot, however, be sufficiently controlled and the latency from the onset of thermal stimulus to the onset of sensation varies considerably..$^{18}$ Nowadays thermostimulators operating on the Peltier principle are commonly used. The "Marstock" thermostimulator is attached to the hand or the foot and can be warmed or cooled alternatively, depending on the direction of the current applied. ${ }^{5}$ As soon as the patient perceives warmth or cold he reverses the current by turning a switch. Thus a record is obtained that is a measurement of the temperature interval between the perception of cold and warmth. This method is not, however, free of response bias. Moreover, the variable time of reaction to the ther- 
mal stimulus can affect the measurement. ${ }^{519}$ For this reason, we selected the two-alternative forcedchoice procedure, making use of two identical thermostimulators. The forced-choice method is an accurate and widely accepted psychophysiological test procedure which is free of criterion and response bias artifacts. ${ }^{20-23}$ Ignoring the first two reversal points, and using the criteria mentioned to judge an answer as being correct or incorrect, the test method is more reliable. ${ }^{122-24}$

Because the temperature of the "neutral" stimulator equals the skin temperature, and the second stimulator is either warmer or cooler, both warmth and cold receptors are tested. Although there are differences between cold and warm perception, there is no evidence that neuropathy affects these qualities separately. Thermal discrimination is related to the skin temperature, and therefore it is essential to involve the temperature of the stimulated area in the determination of the thermal discrimination threshold. ${ }^{2 s}$

In our method, we chose a combination of thermal stimulus with a tactile stimulus. Because a variable stimulus pressure can affect thermal sensation, ${ }^{26}$ the pressure was kept constant at 200 gram.

The results we obtained on examining normal subjects are comparable with those of Kenshalo et $a^{8}{ }^{8}$ and Dyck et al. ${ }^{6}$ Although most investigators postulate a decreased cutaneous sensation with advancing age, only a few studies dealing with this theme have been published. ${ }^{37232728}$ Dyck et al ${ }^{37}$ investigated thermal cutaneous sensation in elderly subjects and found impaired thermal discrimination with increasing age. Our findings-especially for the foot-confirm this age-related difference in thermal discrimination thresholds. Several factors have been advanced to account for this "age-neuropathy". Some properties of the skin vary with age. There is a decrease in total numbers of cutaneous receptors and myelinated fibres and those receptors that remain are irregularly distributed and vary in size and shape. Other factors could be inadequate blood flow to the spinal cord and diminished blood flow in peripheral structures. ${ }^{23} 2728$

Our findings in patients with diabetic neuropathy suggest a considerably impaired small fibre function, sometimes in the presence of normal clinical or neurophysiological findings or in the absence of complaints. The difference we found between thermal discrimination thresholds for the hand and for the foot confirms the length-dependent nature of nerve degeneration in diabetic neuropathy. ${ }^{49}$

We found a small intra-individual variability of thermal discrimination threshold in all normal subjects and in most diabetic patients. A considerable difference between the two examinations for the foot was found in three patients (fig 4). A major factor influencing sensory threshold determinations is the attention of the subject. ${ }^{29}$ In diabetic patients this attention can be affected by fluctuation of blood glucose levels. Therefore we recommend the use of the mean value of two examinations in order to determine discrimination thresholds. This is in accordance with findings of Fagius and Wahren. ${ }^{29}$ Bearing this in mind we consider determination of thermal discrimination thresholds in patients with diabetes mellitus a valuable method by which to diagnose neuropathy. The method can be of particular importance when monitoring of sensory function is required, as is the case in clinical trials with drugs which are claimed to improve nerve function in diabetes mellitus.

We thank Dr Ir PO Bezemer and Dr PJ Kostense (Department of Medical Statistics) for their comments and advice. The equipment was developed in collaboration with Mr R Heslinga of the instrumental department of the Free University Hospital.

\section{References}

' Dyck PJ, Zimmerman JR, O'Brien PC, et al. Introduction of automated systems to evaluate touch pressure, vibration, and thermal cutaneous sensation in man. Ann Neurol 1978;4:502-10.

${ }^{2}$ Conomy JP, Barnes KL, Conomy JM. Cutaneous sensory function in diabetes mellitus. $J$ Neurol Neurosurg Psychiatry 1979;42:656-61.

${ }^{3}$ Dyck PJ, Karnes J, O'Brien PC, Zimmerman IR. Quantitation of cutaneous sensation in man. In: Dyck PJ, Thomas PK, Lambert EW, Bunge R, eds. Peripheral Neuropathy. Philadelphia: Saunders, 1984;1:1103 38.

4 Said G, Slama G, Selva J. Progressive centripetal degeneration of axons in small fibre diabetic polyneuropathy. A clinical and pathological study. Brain 1983;106: 791-807.

5 Frühstorfer H, Lindblom U, Schmidt WG. Method for quantitative estimation of thermal thersholds in patients. J Neurol Neurosurg Psychiatry 1976;39:1071-5.

' Dyck PJ, Lambert EW, Nichols PC. Quantitative measurement of sensation related to compound action potential and number and sizes of myelinated and unmyelinated fibers of sural nerve in health, Friedreich's ataxia, hereditary sensory neuropathy, and tabes dorsalis. In: Remond A, ed. Handbook of Electroencephalography and Clinical neurophysiology. Amsterdam: Elsevier Press Inc., 1971;9:83-118.

7 Dyck RJ, Curtis DJ, Bushek W, Offord K. Description of 'Minnesota Thermal Disks' and normal values of cutaneous thermal discrimination in man. Neurology (Minneap) 1974;24:325-30.

${ }^{8}$ Kenshalo DR, Nafe JP, Dawson WW. A new method for 
the investigation of thermal sensitivity. J Psychol 1960;49:29-41.

${ }^{9}$ Brown MJ, Asbury AK. Diabetic Neuropathy. Ann Neurol 1984;15:2-12.

${ }^{10}$ Dorfman LJ, Cummins KL, Reaven GM, Ceranski J, Greenfield MS, Doberne L. Studies of diabetic polyneuropathy using conduction velocity distribution (DCV) analysis. Neurology (NY) 1983;33:773-9.

" Hensel H. Cutaneous thermoreceptors. In: Iggo A, ed. Handbook of Sensory Physiology. New York: Springer, 1973;2:79-110.

12 Strian F, Severin F, Müller J, Montag N. Diagnose der diabetischen 'painful small fibre neuropathy' mit Hilfe der Temperaturempfindlichheitsschwellen. Nervenarzt 1984;55:103-7.

${ }^{13}$ Fagius $\mathbf{J}$, Jameson $\mathbf{S}$. Effects of aldose reductase inhibitor treatment in diabetic neuropathy - a clinical and neurophysiological study. J Neurol Neurosurg Psychiatry 1981;44:991-1001.

14 Young RJ, Ewing DJ, Clarke BF. A controlled trial of sorbinil, an aldose reductase inhibitor in chronic painful diabetic neuropathy. Diabetes $1983 ; 32$ :938-42.

is Service FJ, Daube JR, O'Brien PC, Dyck PJ. Effect of artificial pancreas treatment on peripheral nerve function in diabetes. Neurology (NY) 1981;31:1375-80.

${ }^{16}$ Boulton AJM, Drury J, Clarke B, Ward JD. Continuous subcutaneous insulin infusion in the management of painful diabetic neuropathy. Diabetes care 1982;5:386-90.

${ }^{17}$ Sinclair D. Cutaneous Sensation. Oxford University Press, 1967.

18 Wright GH. The latency of sensations of warmth due to radiation. J Physiol (Lond) 1951;112:344-58.

${ }^{19}$ Lele PP, Sinclair DC. Observations on the reaction time to cutaneous thermal stimuli. J Neurol Neurosurg Psychiatry 1955;18:120-4.

${ }^{20}$ Cornsweet TN. The staircase method in psychophysics. Am J Psychol 1962;75:485-91.

${ }^{21}$ Sekuler R, Nash D, Armstrong R. Sensitive, objective procedure for evaluating response to light touch. Neurology (Minneap) 1973;23:1282-91.

${ }^{22}$ McBride MR, Mistretta CM. Light touch thresholds in diabetic patients. Diabetes Care 1982;5:34-9.

${ }^{23}$ Thornbury JM, Mistretta CM. Tactile sensitivity as a function of age. J Gerontol 1981;36:34-9.

${ }^{24}$ Wetherhill GB, Chen H, Vasudeva RB. Sequential estimation of quantal response curves: a new method of estimation. Biometrika 1966;53:439-54.

${ }^{25}$ Lele PP. Relationship between cutaneous thermal thresholds, skin temperature and cross-sectional area of the stimulus. J Physiol (Lond) 1954;126:191-205.

${ }^{26}$ Heiser F, McNair WK. Stimulus pressure and thermal sensation. Am J Psychol 1934;46:580-9.

${ }^{27}$ Corso JF. Sensory processes and age effects in normal adults. J Gerontol 1971;26:90-105.

${ }^{28}$ Kenshalo DR. Age changes in touch, vibration, temperature kinesthesis and pain sensitivity. In: Birren JE, Schaie KW, eds. Handbook of the Psychology of Aging. New York: Van Nostrand Reinhold, 1977;562-80.

${ }^{29}$ Fagius J, Wahren LK. Variability of sensory threshold determination in clinical use. $J$ Neurol $S c i$ 1981;51:11-27. 